\title{
ORTOPIROXÊNIOS E CLINOPIROXÊNIOS COEXISTENTES NOS GRANULITOS DE SÃO JOSÉ DO RIO PARDO, SP
}

\author{
MARCOS AURELIO FARIAS DE OLIVEIRA* e RAPHAEL HYPOLITO*
}

\begin{abstract}
Orthopyroxenes and clinopyroxenes-bearing granulites from the migmatitic-granulitic region of São José do Rio Pardo, São Paulo, Brazil have been analyzed by electron microprobe.

The distribution coeficient Fe-Mg and the crystallization trends of the analyzed 9 pairs of clino-and orthopyroxenes, are consistent with the formation of these minerals under highgrade metamorphic conditions. A regional temperature of about $795-883^{\circ} \mathrm{C}$ has been infer. red using the geothermometer of Wood and Banno (1973).
\end{abstract}

INTRODUÇÃo O problema do equilíbrio ortopiroxênio-clinopiroxênio tanto em rochas ígneas, como em rochas metamórficas profundas, tem sido amplamente investigado na literatura geológica mais recente, principalmente tendo em vista que tal equilíbrio tem se revelado um termômetro geológico de razoável precisão. Desta forma, considerando as numerosas ocorrências em que se registra a coexistência desses minerais na região de São José do Rio Pardo, julgou-se interessante uma pesquisa mais pormenorizada a esse respeito.

A geologia da área, constituída por um complexo migmatítico-granulítico, acha-se descrita em Oliveira (1973) e Oliveira e Alves (1974). Além disso, a localização das amostras analisadas, os dados modais de algumas delas e os caracteres físicos dos piroxênios estudados constam também do trabalho de Oliveira (1973).

$\mathrm{Na}$ escolha das amostras analisadas, procurou-se selecionar tipos que mostram uma gama completa de variação da relação $\mathrm{Mg} / \mathrm{Fe}$ para se observar se o equilíbrio é completo ao longo da série, e para se obter um maior intervalo no "trend" de variação dos piroxênios. Para isso, baseou-se na observação de Öliveira (1972) de que os granulitos mais ácidos possuem ortopiroxênios mais ricos na molécula ferrossilita, sendo os mais básicos ricos na molécula enstatita. Por outro lado, foi dada preferência às amostras já analisadas quimicamente e, portanto, com teor em $\mathrm{SiO}_{2}$ conhecido. Dos tipos selecionados, 4 são gabro-noríticos $(180,111,217$ e 136), 1 é monzonítico (201), 3 são graníticos $(168,176$ e 205); uma última amostra (226) é nitidamente parametamórfica e constitui-se de hiperstênio, granada, clinopiroxênio, plagioclá. sio, quartzo, grafita e opacos e foi escolhida para se observar seu comportamento com relação aos demais tipos, de origem mais incerta. O teor de piroxênios nas amostras analisadas varia de $26 \%$, nos tipos mais básicos, a $4 \%$, nos mais ácidos, chegando a $2 \%$ no granulito 168 , o que dificultou bastante sua análise na microssonda.

CARACTERES QUÍMICOS D Com exceção da amostra 136, todas as rochas que tiveram seus piroxênios analisados contam com análise química completa, obtida por via úmida. Destas, cinco şão reproduzidas de Oliveira (1973) e três são inéditas. Os valores constam da Tabela I. Quanto aos dados químicos dos piroxênios, eles se acham representados nas Tabs. II (ortopiroxênios) e III (clinopiroxênios) e foram 
obtidos por microssonda eletrônica, utilizando um aparelho EMX-SM da Applied Research Laboratories, do Instituto de Geociências da Universidade de São Paulo. As condições instrumentais foram as seguintes: potencial de aceleração de $15 \mathrm{kV}$, corrente da amostra de $0,03 \mu \mathrm{A}$, tempo de integração de 20 segundos e diâmetro do feixe eletrônico de aproximadamente $1 \mu$. A quantidade de raios $\mathrm{X}$ emitida (radiação $\mathrm{K} \alpha$ ) foi detectada simultaneamente por três espectrômetros lineares equipados com cristais de LiF, ADP e RAP. Os padrões utilizados foram substâncias naturais, um clinopiroxênio cálcico (5-118) e um ortopiroxênio (2525). Foram feitas correções para desvio instrumental, radiação de fundo e efeitos de matriz, empregando-se o método de BENCE \& ALBEE (1968). Cada análise corresponde a uma média de 30 a 35 determinações de cada mineral em uma secção delgada. Foram feitas também medidas na borda e centro dos grãos, e verificou-se não haver zoneamento em qualquer das amostras analisadas.

Tabela I - Análises químicas de granulitos da região de São José do Rio Pardo

\begin{tabular}{lrrrrrrrr}
\hline & $180^{*}$ & $111^{*}$ & 217 & $201^{*}$ & 168 & $176^{*}$ & $205^{*}$ & 226 \\
& & & & & & & & \\
$\mathrm{SiO}_{2}$ & 46,20 & 49,90 & 52,21 & 47,38 & 63,02 & 61,86 & 63,84 & 49,37 \\
$\mathrm{TiO}_{2}$ & 1,50 & 1,18 & 0,83 & 0,14 & 0,87 & 1,20 & 0,80 & 0,56 \\
$\mathrm{Al}_{2} \mathrm{O}_{3}$ & 16,20 & 12,46 & 19,40 & 17,33 & 18,45 & 15,70 & 15,14 & 14,90 \\
$\mathrm{Fe}_{2} \mathrm{O}_{3}$ & 6,94 & 8,48 & 2,59 & 3,75 & 1,29 & 2,33 & 3,02 & 8,11 \\
$\mathrm{FeO}$ & 9,17 & 10,05 & 7,47 & 5,59 & 3,46 & 4,49 & 3,26 & 14,06 \\
$\mathrm{MnO}$ & 0,19 & 0,21 & 0,10 & 0,20 & 0,06 & 0,18 & 0,11 & 0,20 \\
$\mathrm{MgO}$ & 7,20 & 3,50 & 3,34 & 1,60 & 0,94 & 1,50 & 0,87 & 7,57 \\
$\mathrm{CaO}$ & 8,04 & 7,12 & 9,19 & 3,63 & 2,70 & 4,82 & 2,89 & 4,15 \\
$\mathrm{Na}_{2} \mathrm{O}$ & 3,20 & 4,40 & 3,01 & 4,05 & 5,53 & 3,65 & 4,45 & 0,27 \\
$\mathrm{~K}_{2} \mathrm{O}$ & 0,52 & 1,70 & 1,18 & 5,40 & 3,31 & 3,60 & 5,05 & 0,08 \\
$\mathrm{H}_{2} \mathrm{O}^{+}$ & 0,60 & 0,14 & 0,21 & 0,45 & 0,03 & 0,35 & 0,38 & 0,27 \\
$\mathrm{H}_{2} \mathrm{O}^{-}$ & 0,03 & 0,20 & 0,19 & 0,11 & 0,06 & 0,05 & 0,02 & 0,18 \\
$\mathrm{P}_{2} \mathrm{O}_{5}$ & 0,18 & 0,57 & 0,04 & 0,11 & 0,11 & 0,15 & 0,12 & 0,05 \\
$\mathrm{Total}$ & 99,98 & 99,91 & 99,76 & 99,74 & 99,83 & 99,88 & 99,95 & 99,77 \\
$\mathrm{Fe} \mathrm{Total} \mathrm{como} \mathrm{FeO}$ & 15,42 & 17,68 & 9,80 & 8,96 & 4,62 & 6,59 & 5,98 & 21,36 \\
$\mathrm{MgO} / \mathrm{FeO}+\mathrm{MgO}$ & 0,32 & 0,17 & 0,25 & 0,15 & 0,17 & 0,18 & 0,13 & 0,26 \\
\hline
\end{tabular}

* Extraidas de Oliveira (1973)

Além dos dados químicos relacionados, constam também das Tabs. II e III a fórmula química dos piroxênios, alguns índices de diferenciação, os valores do coeficiente de distribuição $\mathrm{Fe}-\mathrm{Mg}$, conforme Davidson (1968), e as temperaturas calculadas com base no termômetro de Wood \& Banno (1973).

Nos granulitos mais ácidos, os cristais de piroxênios se apresentam em grãos isolados, enquanto que nos tipos mais básicos eles ocorrem geralmente envolvidos por hornblenda, ou mais raramente biotita. Os órtopiroxênios são mais susceptíveis às transformações retrometamórficas e freqüentemente são substituídos total ou parcialmente por hornblenda verde, ou por um agregado de filossilicatos verdes. Nas amostras 205 e 176 , alguns grãos de clinopiroxênios exibem lamelas de exsolução muito finas de ortopiroxênios. 
Tabela II - Análises químicas de ortopiroxênios

\begin{tabular}{|c|c|c|c|c|c|c|c|c|c|}
\hline & 180 & 217 & 168 & 111 & 136 & 201 & 176 & 205 & 226 \\
\hline $\mathrm{SiO}_{2}$ & 51,13 & 50,99 & 51,62 & 50,01 & 50,30 & 48,70 & 49,18 & 48,18 & 50,58 \\
\hline $\mathrm{TiO}_{2}$ & 0,02 & 0,03 & 0,02 & 0,03 & 0,03 & 0,2 & 0,03 & 0,03 & 0,02 \\
\hline $\mathrm{Al}_{2} \mathrm{O}_{3}$ & 1,60 & 1,61 & 0,03 & 1,07 & 0,96 & 0,99 & 0,68 & 0,90 & 0,68 \\
\hline $\mathrm{FeO}^{*}$ & 25,17 & 25,43 & 28,91 & 32,06 & 34,12 & 33,57 & 36,28 & 39,15 & 31,34 \\
\hline $\mathrm{MnO}$ & 0,84 & 0,70 & 0,78 & 0,81 & 1,10 & 1,83 & 1,34 & 1,28 & 2,94 \\
\hline $\mathrm{MgO}$ & 21,25 & 18,89 & 17,10 & 14,19 & 13,12 & 12,34 & 11,18 & 8,30 & 13,16 \\
\hline $\mathrm{CaO}$ & 0,93 & 1,10 & 0,75 & 1,14 & 0,93 & 1,22 & 1,26 & 1,38 & 0,98 \\
\hline $\mathrm{Na}_{2} \mathrm{O}$ & 0,03 & 0,06 & 0,01 & 0,12 & 0,11 & 0,12 & 0,09 & 0,16 & 0,01 \\
\hline $\mathrm{K}_{2} \mathrm{O}$ & 0,02 & 0,02 & 0,01 & 0,03 & 0,03 & 0,03 & 0,03 & 0,04 & 0,01 \\
\hline Total & 101,00 & 98,83 & 100,02 & 99,45 & 100,70 & 99,82 & 100,05 & 99,43 & 99,72 \\
\hline
\end{tabular}

Si

$\mathrm{Al}^{\mathrm{lv}}$

$A l^{\mathrm{vl}}$

Ti

$\mathrm{Fe}$

Mn

$\mathrm{Mg}$

$\mathrm{Ca}$

$\mathrm{Na}$

K

$\mathrm{Z}$

WXY

$\mathrm{Ca}$

$\mathrm{Mg}$

$\mathrm{Fe}+\mathrm{Mn}$

\begin{tabular}{cccccccccc}
$\frac{\mathrm{MgO}}{\mathrm{MgO}+\mathrm{FeO}}$ & 0,46 & 0,43 & 0,37 & 0,31 & 0,28 & 0,27 & 0,24 & 0,18 & 0,30 \\
$\frac{\mathrm{MgO}}{\mathrm{FeO}}$ & 0,84 & 0,74 & 0,59 & 0,44 & 0,38 & 0,37 & 0,31 & 0,23 & 0,42 \\
$\frac{\mathrm{Fe}}{\mathrm{Mg}+\mathrm{Fe}}$ & 0,40 & 0,43 & 0,49 & 0,56 & 0,59 & 0,60 & 0,65 & 0,73 & 0,57 \\
$\frac{\mathrm{Fe}}{\mathrm{Mg}}$ & 0,66 & 0,76 & 0,95 & 1,27 & 1,46 & 1,52 & 1,82 & 2,65 & 1,34 \\
$\frac{100 \mathrm{Mg}}{\mathrm{Mg}+\mathrm{Fe}+\mathrm{Mn}}$ & 59,3 & 56,3 & 50,7 & 43,5 & 39,9 & 38,3 & 34,6 & 26,8 & 40,6 \\
$\mathrm{~T}{ }^{\circ} \mathrm{C}^{* *}$ & 872 & 848 & 883 & 825 & 823 & 801 & 802 & 795 & 881 \\
\hline
\end{tabular}

Número de íons na base de 6 oxigênios

$\begin{array}{ccccccccc}1,922 & 1,959 & 1,987 & 1,975 & 1,979 & 1,966 & 1,978 & 1,982 & 2,000 \\ 0,071 & 0,041 & 0,013 & 0,025 & 0,021 & 0,034 & 0,022 & 0,018 & - \\ - & 0,032 & 0,025 & 0,025 & 0,023 & 0,013 & 0,010 & 0,026 & 0,031 \\ - & 0,001 & 0,001 & 0,001 & 0,001 & 0,001 & 0,001 & 0,001 & 0,001 \\ 0,791 & 0,817 & 0,930 & 1,059 & 1,123 & 1,133 & 1,220 & 1,347 & 1,036 \\ 0,027 & 0,023 & 0,025 & 0,027 & 0,036 & 0,063 & 0,045 & 0,044 & 0,098 \\ 1,190 & 1,082 & 0,981 & 0,835 & 0,770 & 0,743 & 0,670 & 0,509 & 0,775 \\ 0,038 & 0,045 & 0,031 & 0,048 & 0,039 & 0,053 & 0,054 & 0,061 & 0,041 \\ 0,002 & 0,041 & 0,001 & 0,009 & 0,008 & 0,009 & 0,007 & 0,013 & 0,001 \\ 0,001 & 0,001 & - & 0,001 & 0,001 & 0,001 & 0,001 & 0,002 & - \\ 2,000 & 2,000 & 2,000 & 2,000 & 2,000 & 2,000 & 2,000 & 2,000 & 2,000 \\ 2,042 & 2,042 & 1,995 & 2,005 & 2,001 & 2,016 & 2,008 & 2,003 & 1,983 \\ 1,9 & 2,3 & 1,6 & 2,4 & 2,0 & 2,7 & 2,7 & 3,1 & 2,1 \\ 58,1 & 55,0 & 49,8 & 42,4 & 39,1 & 37,3 & 33,7 & 26,0 & \mathbf{8 9 , 7} \\ 40,0 & 42,7 & 48,6 & 55,2 & 58,9 & 60,0 & 63,6 & 70,9 & 58,2\end{array}$

* Todo ferro calculado como $\mathrm{FeO}$

** Segundo Wood e Banno (1973) 
Tabela III - Análises químicas de clinopiroxênios

\begin{tabular}{|c|c|c|c|c|c|c|c|c|c|}
\hline & 180 & 217 & 168 & 111 & 136 & 201 & 176 & 205 & 226 \\
\hline $\mathrm{SiO}_{2}$ & 49,18 & 50,45 & 52,69 & 51,04 & 51,63 & 49,64 & 50,28 & 49,22 & 50,11 \\
\hline $\mathrm{TiO}_{2}$ & 0,04 & 0,04 & 0,02 & 0,04 & 0,04 & 0,08 & 0,04 & 0,03 & 0,02 \\
\hline $\mathrm{Al}_{2} \mathrm{O}_{3}$ & 2,74 & 2,95 & 1,64 & 1,81 & 1,70 & 1,77 & 1,30 & 1,45 & 1,12 \\
\hline $\mathrm{FeO} *$ & 10,86 & $.10,62$ & 12,48 & 14,91 & 15,73 & 16,29 & 17,81 & 20,70 & 13,96 \\
\hline $\mathrm{MnO}$ & 0,40 & 0,85 & 0,34 & 0,41 & 0,50 & 0,92 & 0,68 & 0,70 & 1,35 \\
\hline $\mathrm{MgO}$ & 18,75 & 12,40 & 11,99 & 10,55 & 9,79 & 9,67 & 8,76 & 6,89 & 10,51 \\
\hline $\mathrm{CaO}$ & 21,24 & 21,28 & 20,01 & 20,39 & 19,99 & 20,13 & 20,03 & 19,55 & 20,33 \\
\hline $\mathrm{Na}_{2} \mathrm{O}$ & 0,47 & 0,44 & 0,66 & 0,58 & 0,56 & 0,65 & 0,53 & 0,58 & 0,24 \\
\hline $\mathrm{K}_{2} \mathrm{O}$ & 0,02 & 0,01 & 0,02 & 0,04 & 0,02 & 0,03 & 0,02 & 0,03 & 0,01 \\
\hline Total & 98,70 & 98,54 . & 99,84 & 99,76 & 99,96 & 99,12 & 99,45 & 99,15 & 97,63 \\
\hline
\end{tabular}

Número de fons na base de 6 oxigênios

\begin{tabular}{|c|c|c|c|c|c|c|c|c|c|c|}
\hline $\mathrm{Si}$ & & 1,887 & 1,927 & 1,988 & 1,959 & 1,980 & 1,940 & 1,966 & 1,959 & 1,969 \\
\hline $\mathrm{Al}^{\mathrm{Iv}}$ & & 0,113 & 0,073 & 0,012 & 0,041 & 0,020 & 0,060 & 0,034 & 0,041 & 0,031 \\
\hline $\mathrm{Al}^{\mathrm{vl}}$ & & 0,011 & 0,060 & 0,061 & 0,041 & 0,057 & 0,021 & 0,026 & 0,027 & $.0,021$ \\
\hline $\mathbf{T i}$ & & 0,001 & 0,001 & - & 0,001 & 0,001 & 0,001 & 0,001 & 0,001 & - \\
\hline Fe. & & 0,348 & 0,339 & 0,394 & 0,479 & 0,504 & 0,533 & 0,582 & 0,689 & 0,459 \\
\hline Mn & & 0,018 & 0,011 & 0,011 & 0,013 & 0,016 & 0,030 & 0,022 & 0,023 & 0,045 \\
\hline $\mathbf{M g}$ & & 0,786 & 0,706 & 0,674 & 0,603 & 0,559 & 0,563 & 0,511 & 0,408 & 0,615 \\
\hline $\mathrm{Ca}$ & & 0,873 & 0,871 & 0,809 & 0,838 & 0,821 & 0,843 & 0,839 & 0,833 & 0,856 \\
\hline $\mathbf{N a}$ & & 0,035 & 0,033 & 0,048 & 0,043 & 0,041 & $.0,049$ & 0,040 & 0,045 & 0,018 \\
\hline $\mathbf{K}$ & & 0,001 & - & 0,001 & 0,002 & 0,001 & 0,001 & 0,001 & 0,001 & - \\
\hline $\mathbf{Z}$ & & 2,000 & 2,000 & 2,000 & 2,000 & 2,000 & 2,000 & 2,000 & $2 ; 000$ & 2,000 \\
\hline WXY & & 2,068 & 2,021 & 1,998 & 2,020 & 2,000 & 2,041 & 2,022 & 2,027 & 2,014 \\
\hline $\mathrm{Ca}$ & & 43,2 & 45,2 & 42,9 & 43,4 & 43,2 & 42,8 & 42,9 & 42,7 & 43,4 \\
\hline $\mathbf{M g}$ & & 38,9 & 36,6 & 35,7 & 31,2 & 29,4 & 28,6 & 26,2 & 20,9 & 31,1 \\
\hline $\mathrm{Fe}+\mathrm{Mn}$ & : & 17,9 & 18,2 & 21,4 & 25,4 & 27,4 & 28,6 & 30,9 & 36,4 & 25,5 \\
\hline$\frac{\mathrm{MgO}}{\overline{\mathrm{FeO}}+\mathrm{MgO}}$ & & 0,56 & 0,54 & 0,49 & 0,42 & 0,38 & 0,49 . & 0,33 & 0,25 & 0,43 \\
\hline$\frac{\mathrm{Fe}}{\mathrm{Mg}}$ & $\times 100$ & 44,3 & 48,0 & 58,4 & 79,4 & 90,2 & 94,7 & 113,9 & 168,9 & 74,6 \\
\hline$\frac{\mathrm{MgO}}{\mathrm{FeO}}$ & & 1,27 & 1,17 & 0,96 & 0,71 & 0,62 & 0,76 & 0,49 & 0,33 & 0,75 \\
\hline $\mathbf{K}_{\mathrm{D}}$ & & 1,50 & 1,57 & 1,62 & 1,60 & 1,62 & 1,61 & $1,60^{\circ}$ & 1,57 & 1,79 \\
\hline
\end{tabular}

* Todo ferro calculado como FeO 
Considerando que Oliveira (1973) evidenciou a existência de "trends" calcoalcalinos para os granulitos dessa região, foram feitas várias tentativas de correlacionar a composição química das rochas com os seus respectivos pares de piroxênios. Destas somente algumas revelaram fatos interessantes como, por exemplo, o mostrado na Fig. 1, onde se acham projetadas as razões $\mathrm{MgO} / \mathrm{FeO}$ dos piroxênios contra o teor em $\mathrm{SiO}_{2}$ das respectivas rochas. Pode-se observar que ocorre realmente um decréscimo da razão $\mathrm{MgO} / \mathrm{FeO}$ dos orto-e clinopiroxênios com o aumènto de sílica, mas o que chama mais a atenção é a existência de duas tendências paralelas para ambos os piroxênios. Esse fato poderia indicar que esses dois eonjuntos tiveram origem a partir de materiais diferentes ou, como alternativa, que se formaram em condições termodinâmicas um pouco diversas. Por outro lado, a Fig. 2 evidencia que $o$ aumento da relação $\mathrm{MgO} / \mathrm{MgO}+\mathrm{FeO}$ dos minerais depende muito pouco do aumento da mesma relação nas rochas. Da mesma forma, nessa figura as amostras 168,217 e 180 têm comportamento diferente e acusam maiores variações quando se modificam os teores de $\mathrm{FeO}$ e $\mathrm{MgO}$ das respectivas rochas.

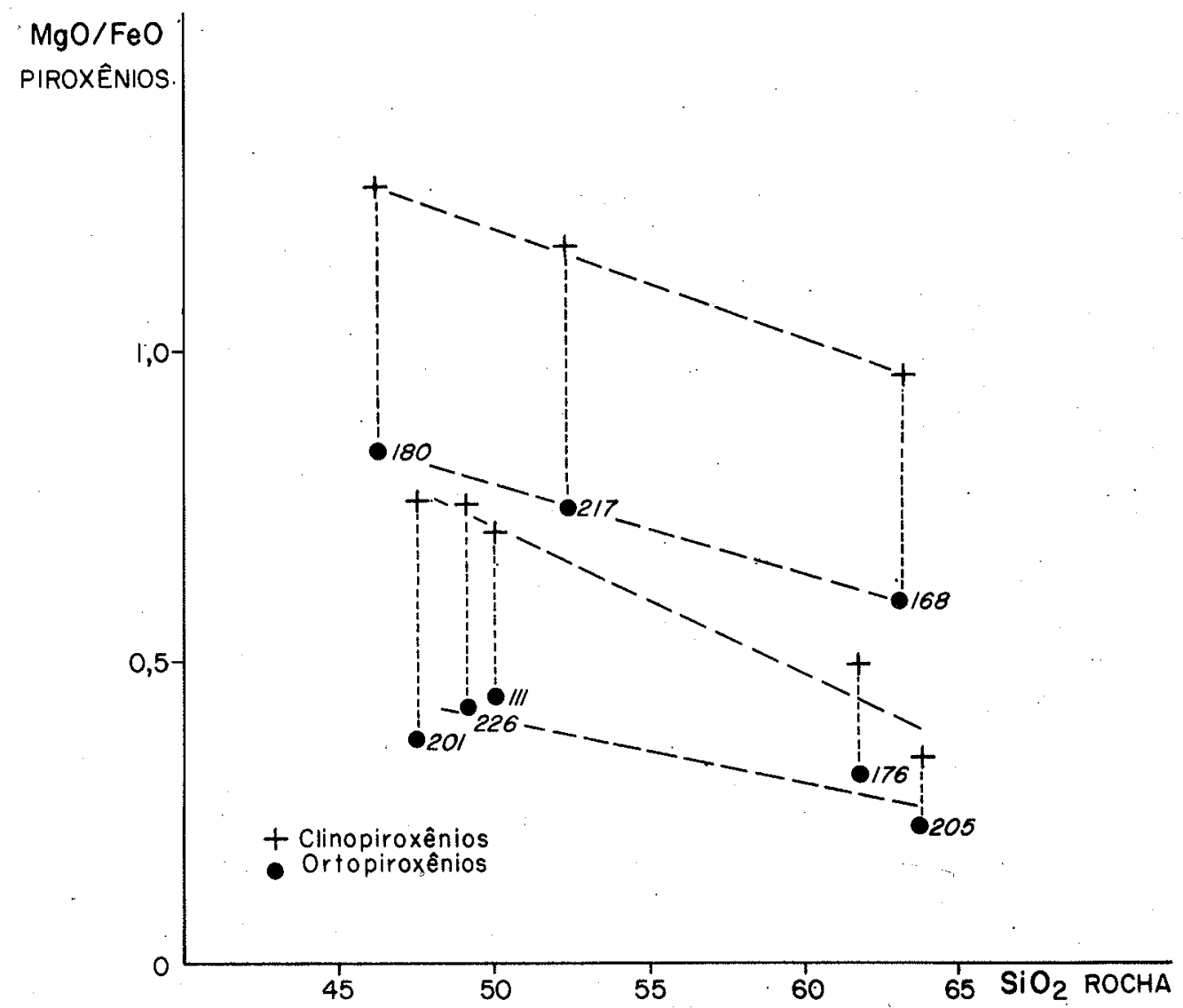

Figura 1 - Projeção da razão $\mathrm{MgO} / \mathrm{FeO}$ dos piroxênios contra o teor em $\mathrm{SiO}_{2}$ das rochas 


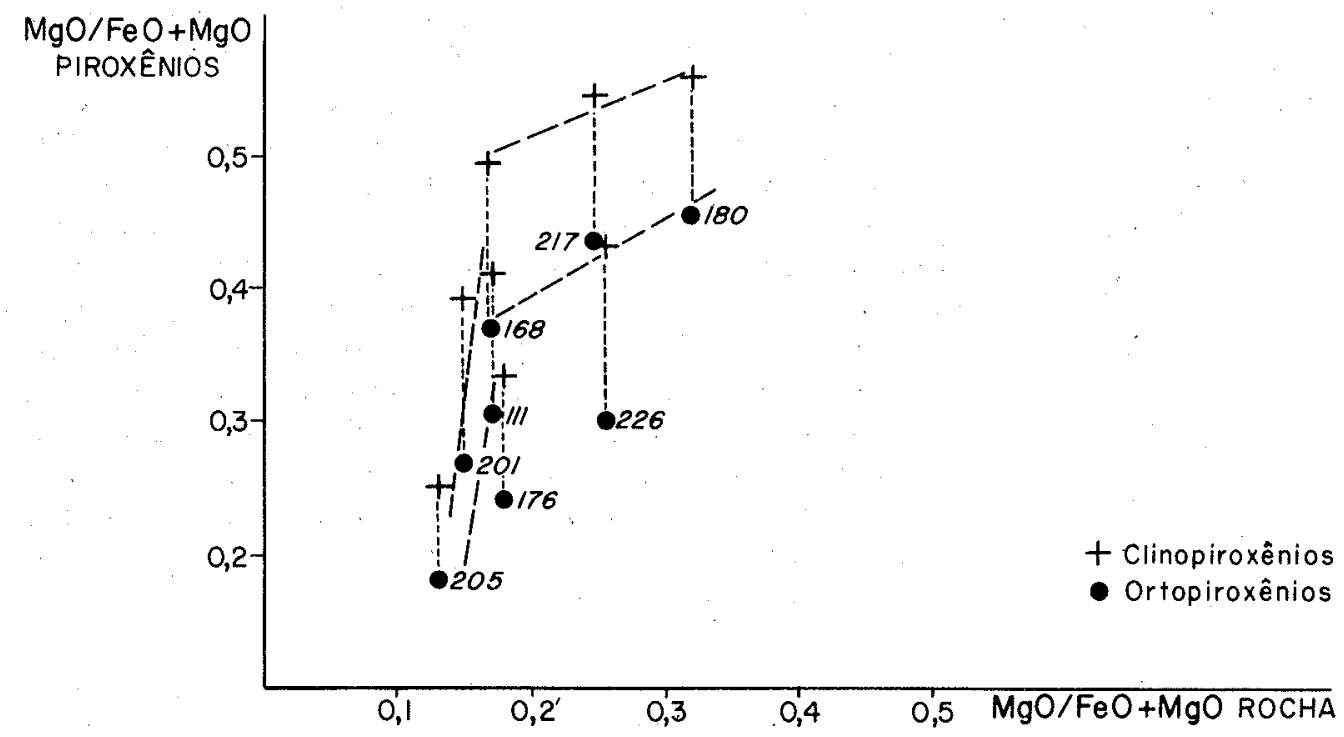

Figura 2 - Projeção da razão $\mathrm{MgO} / \mathrm{FeO}+\mathrm{MgO}$ dos piroxênios contra a mesma razão das rochas

Piroxênios Os nove ortopiroxênios analisados apresentam como caracteristicas mais importantes um teor baixo em $\mathrm{CaO}$, de 0,75 a $1,38 \%$, sendo maior nos tipos graníticos; teores de $\mathrm{Al}_{2} \mathrm{O}_{3}$ variando entre 0,68 a $1,61 \%$, aumentando nas amostras mais ricas em $\mathrm{MgO}$ (Fig. 3); um teor em enstatita situado entre 26 e 58\% (39 a 58\%

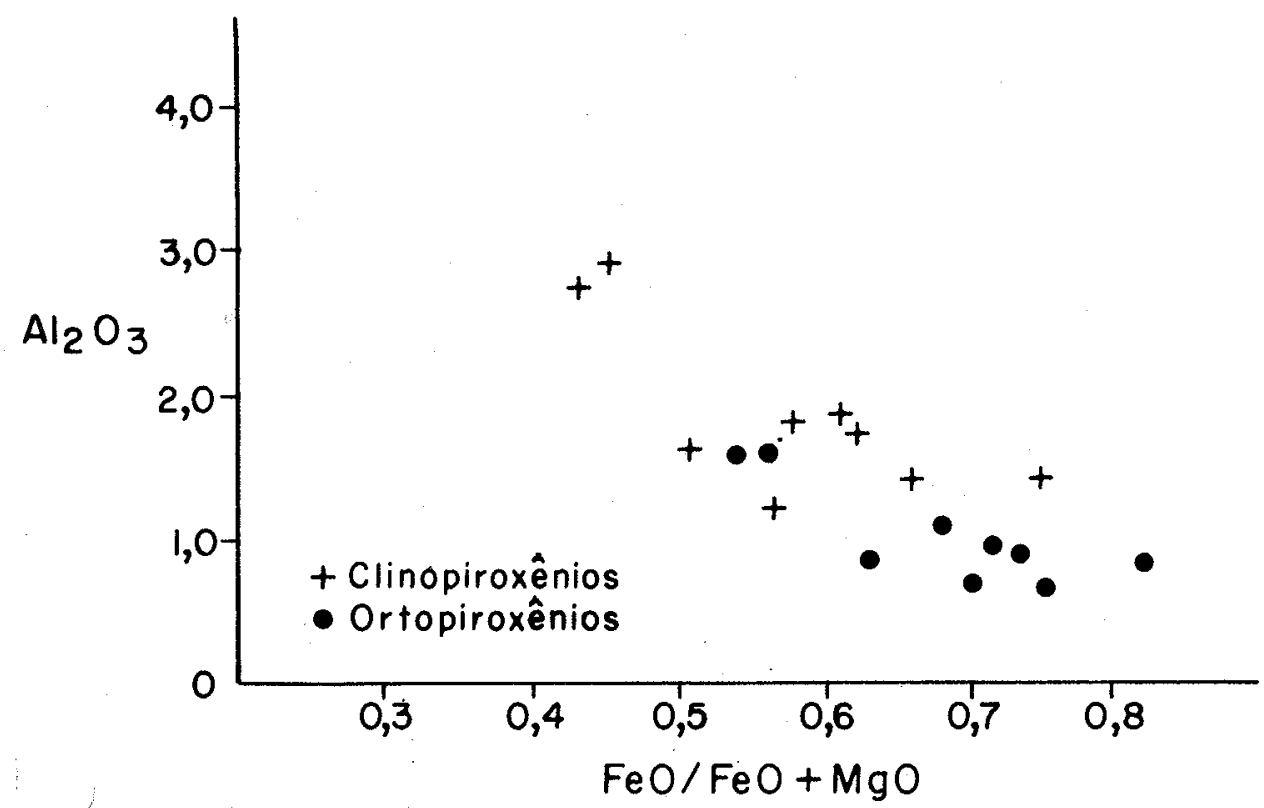

Figura 3 - Projeção do $\mathrm{Al}_{2} \mathrm{O}_{3}$ contra a razão $\mathrm{FeO} / \mathrm{FeO}+\mathrm{MgO}$ 
nos tipos gabro noríticos, $37 \%$ no monzonítico e 26 a $34 \%$ nos graníticos, com exceção da amostra 168 que apresenta 50\%). Pode-se também afirmar, com base no trabalho de Bhattacharyya (1971), que todos os nove ortopiroxênios estudados se cristalizaram ou se recristalizaram por metamorfismo, em virtude dos seus teores elevados em $\mathrm{Al}_{2} \mathrm{O}_{3}, \mathrm{FeO}$ e $\mathrm{MgO}$.

Os clinopiroxênios, por sua parte, caracterizam-se por um teor constante em $\mathrm{CaO}(19,5$ a $21,3 \%)$ e variaçōes maiores nos teores de $\mathrm{FeO}$ e $\mathrm{MgO}$. As quantidades de $\mathrm{Al}_{2} \mathrm{O}_{3}$ se situam entre 1,12 e $2,74 \%$ e, da mesma forma que nos ortopiroxênios, são maiores nos tipos mais ricos em MgO (Fig. 3). São representados pelas variedades salita e ferrosalita da série diopsídio-hedenbergita (DEER et al., 1963).

No quadrilátero diopsídio (Di)-hedenbergita (Hd)-ferrossilita (Fs)-enstatita (En) da Fig. 4, os ortopiroxênios e clinopiroxênios evoluem de maneira similar, sendo essa evolução marcada por um enriquecimento em ferro; por outro lado, observa-se, ao longo da série, uma leve diminuição do $\mathrm{CaO}$ nos clinopịroxênios e um pequeno aumento desse óxido nos ortopiroxênios. $O$ fato das linhas que unem orto e clinopiroxênios de uma mesma rocha não se interceptarem, constitui um argumetno a mais apontando para uma cristalização ou recristalização desses minerais em condições de equilíbrio. Na Fig. 5, observa-se que as tendências de ambos os piroxênios coinci$\mathrm{dem}$, em traços gerais, com as tendências obtidas para rochas metamórficas, ou seja, recobrem aproximadamente as linhas de variação de Madras (Howie, 1955) e Broken Hill-Quairading (Davidson, 1968). O prolongamento dessa curva, em direção ao campo do diopsídio, ensejaria a sua superposição com o "trend" obtido para as rochas de Barra Velha (Soares et al., no prelo). Para fins de comparação, são apresentadas ainda as tendências dos piroxênios metamórficos de Piên (Girardi, 1974) e ígneos de Skaergaard (Brown, 1957; Brown e Vincent, 1963).

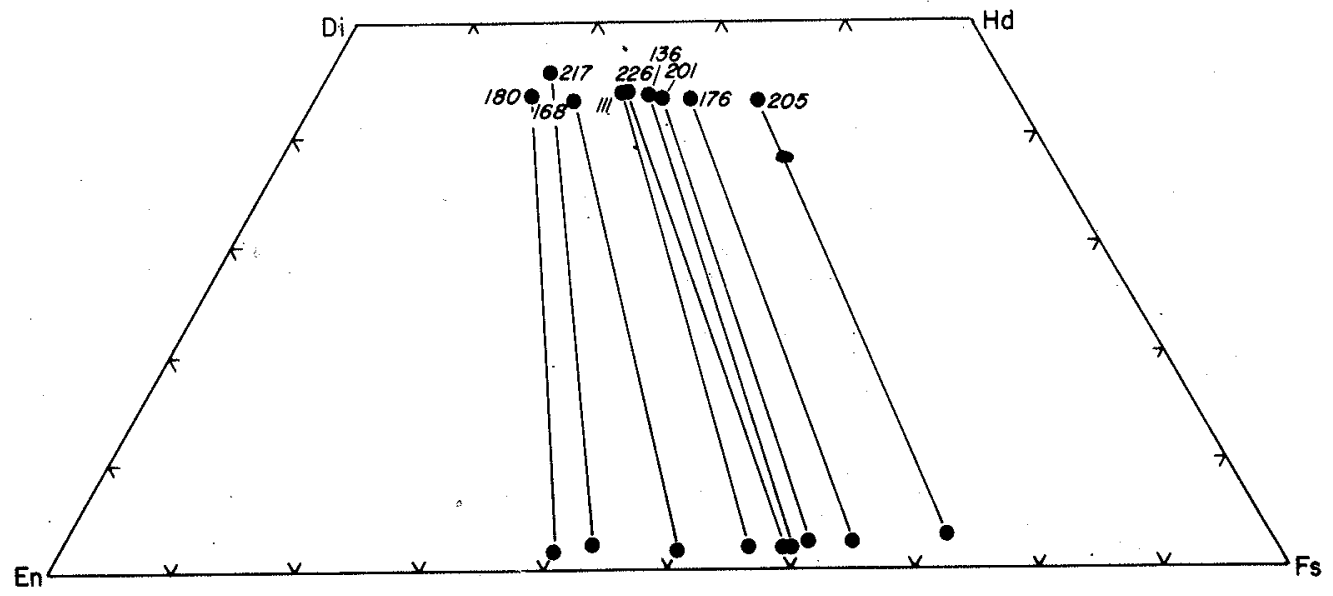

Figura 4 - Composição química dos clino e ortopiroxênios coexistentes, dada pelas porcentagens em peso dos termos extremos $\mathrm{CaSiO}_{3} / \mathrm{MgSiO}_{3}: \mathrm{FeSiO}_{3}$. 


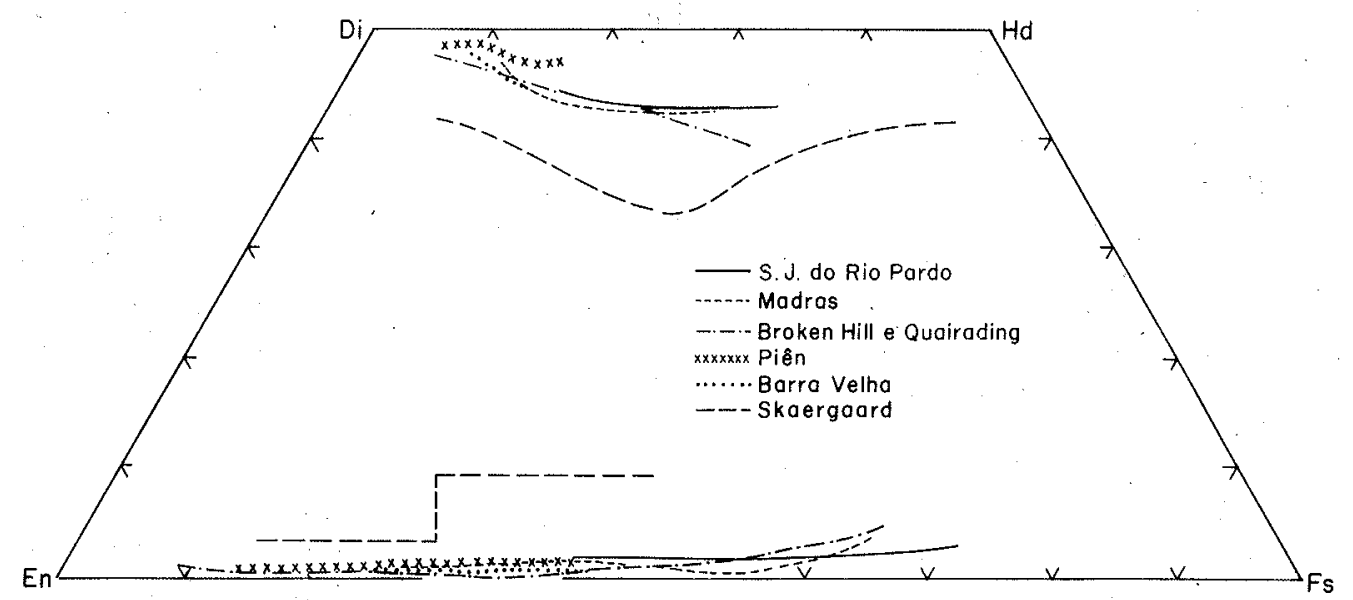

Figura 5 - Tendências de cristalização dos piroxênios de São José do Rio Pardo, comparadas às tendências das províncias metamórficas de Madras (Howie, 1955), Broken Hill e Quairading (Davidson, 1958), Piên (Girardi, 1974), Barra Velha (Soares et al., no prelo) e da intrusão de Skaergaard (Brown, 1957; Brown e Vincent, 1963).

Ainda com referência ao conteúdo de alumínio dos piroxênios de São José do Rio Pardo, pode-se dizer que ele é pequeno quando comparado às análises de outros terrenos granulíticos como, por exemplo, a região de Fraser Range, Austrália, estudada por Wilson (1976). Observa-se, porém, a mesma relação linear obtida por esse autor (Fig. 6). No mesmo diagrama, acham-se tambêm projetados os valores de

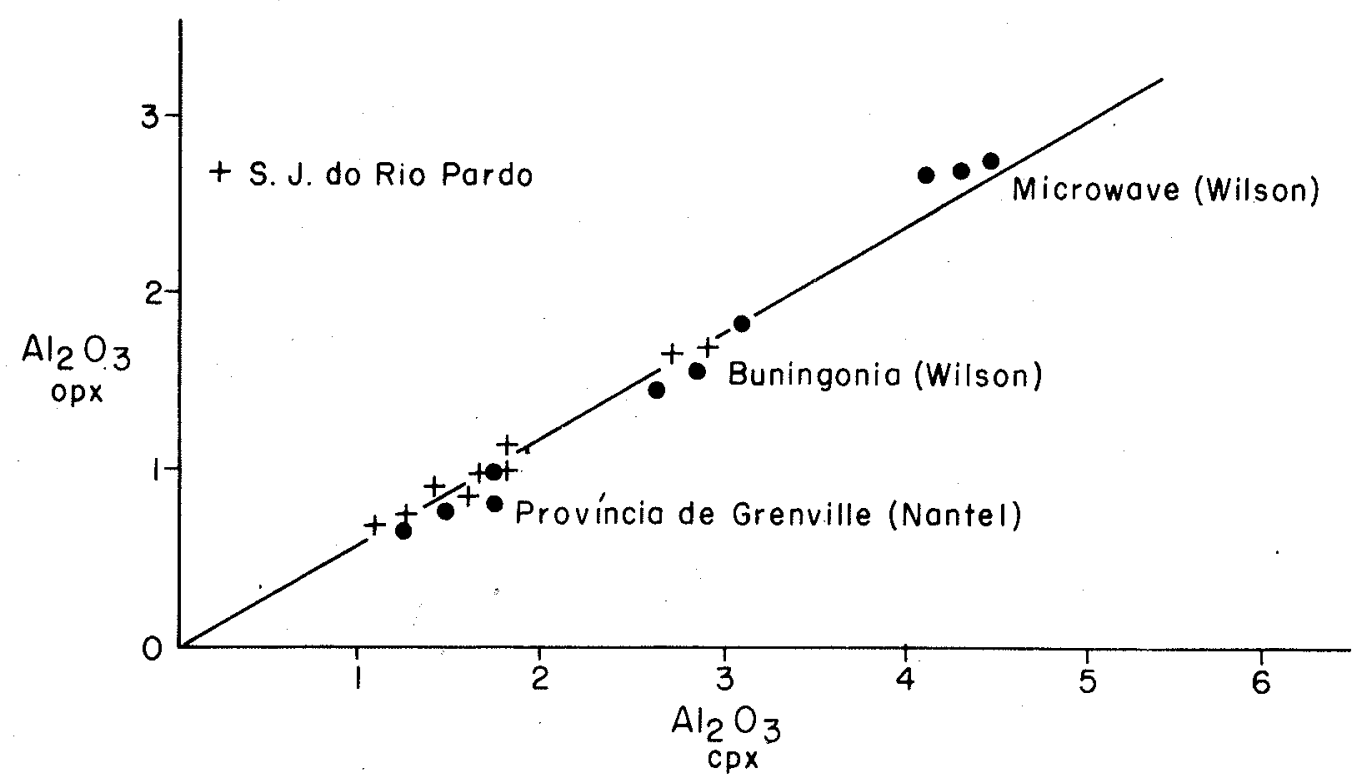

Figura 6 - Relação $\mathrm{Al}_{2} \mathrm{O}_{3} \mathrm{opx}-\mathrm{Al}_{2} \mathrm{O}_{3} \mathrm{cpx}$ para os pares de Wilson (1976), Nantel (1977) e São José do Rio Pardo 
Nantel (1977) para os granulitos do sul da Província de Grenville, Canadá. Esta relação linear evidenciada pela repartição do alumínio entre os dois tipos de piroxênio, e demonstrada também por Ewart et al. (1973), representa uma evidência adicional a favor de um estado de equilíbrio termodinâmico entre os dois minerais.

COEFICIENTES DE DISTRIBUIÇÃO Fe-Mg Tendo em vista que as, análises fornecidas pela microssonda não permitem distinguir entre $\mathrm{Fe}^{2+} \mathrm{Fe}^{8+}$, os coeficientes de distribuição dos elementos $\mathrm{Fe}$ e $\mathrm{Mg}$ foram calculados segundo a fórmula $\mathrm{K}_{\mathrm{D}}$ $\left(\mathrm{Fe}_{\mathrm{tot}}\right)$ opx-cpx = $\left(\mathrm{Fe}_{\mathrm{tot}} / \mathrm{Mg}\right)$ opx $\left(\mathrm{Fe}_{\mathrm{tot}} / \mathrm{Mg}\right) \mathrm{cpx}$, como sugerido por Davidson (1968) e Capedri et al. (1976), e os resultados obtidos desta maneira são recíprocos daqueles obtidos utilizando-se a relação de Kretz (1963). Os valores encontrados no presente trabalho variam de 1,50 a 1,79 , sendo a média 1,60 (Tab. III), e são comparáveis aos fornecidos por Davidson (1968) para os granulitos de Quairading e por Nantel (1977) para os granulitos da Província de Grenville, terrenos tipicamente metamórficos. São apenas um pouco menores, pois os coeficientes calculados com ferro total apresentam resultados ligeiramente inferiores $(0,2$ a 0,5$)$.

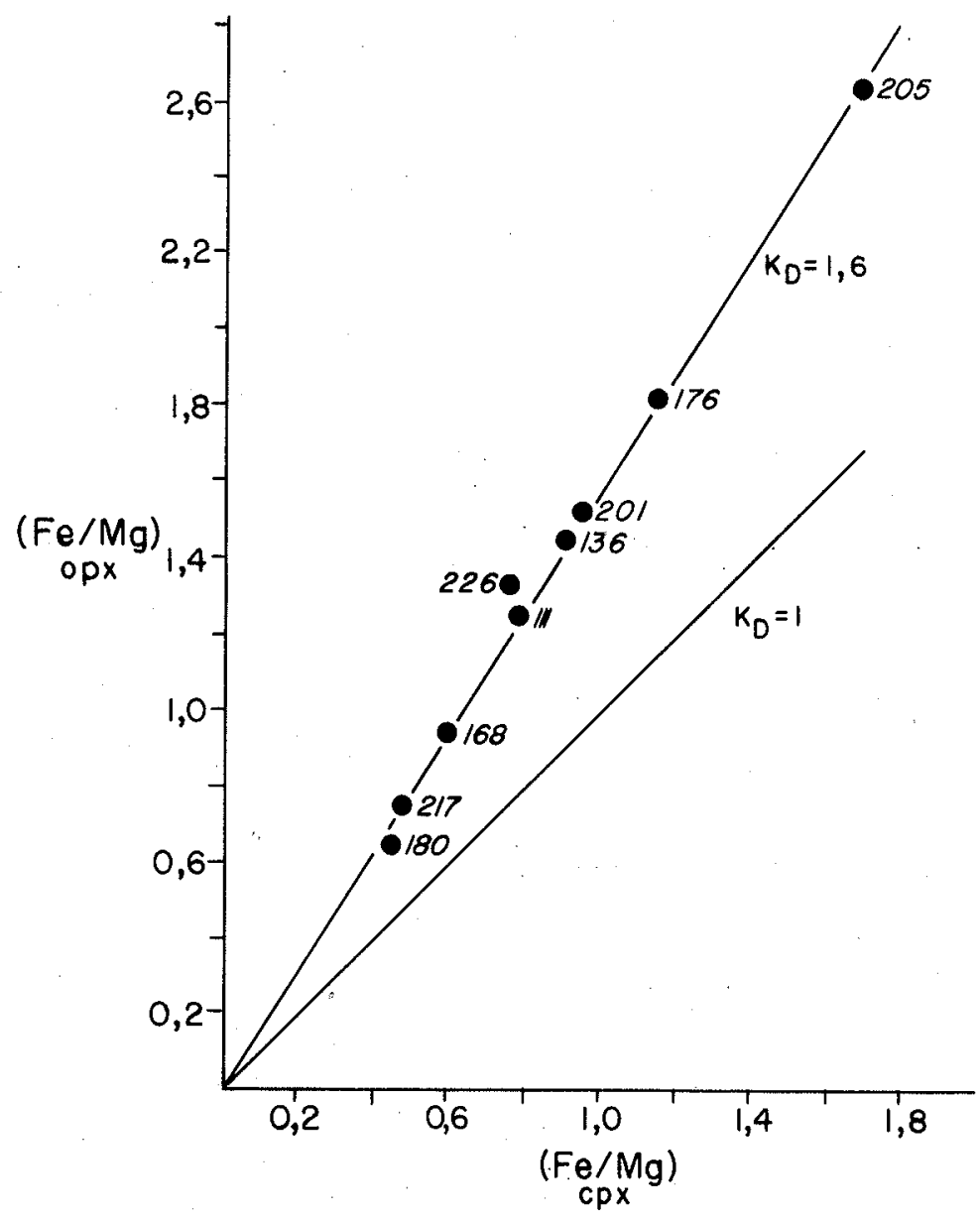

Figúra 7 - Diagrama Fe/Mg opx $-\mathrm{Fe} / \mathrm{Mg} \mathrm{cpx} . \mathrm{K}_{\mathrm{D}}=1,6$ 
$O$ comportamento retílineo dos valores de $K_{D}$ (Fig. 7) indica mais uma vez que os piroxênios estudados estão também em equilíbrio, relativamente a $\mathrm{Fe}$ total $\mathrm{e} \mathrm{Mg}$, embora mostrem pequenas variações quando projetados contra a razão $\mathrm{Fe} / \mathrm{Fe}+\mathrm{Mg}$ dos ortopiroxênios (Fig. 8). Esse fato, já observado por Davidson (1968) para as rochas da Austrália, levou esse autor a sugerir que a aplicação desses coeficientes para estudos regionais, como determinação de valores termodinâmicos, fosse feita somente no caso de áreas onde os piroxênios apresentam largos intervalos de variação no conteúdo de $\mathrm{Fe}$ e $\mathrm{Mg}$, visto que esse parâmetro varia também com a composição. Pode-se observar na Fig. 8 que os valores do $K_{D}$ aumentam e, em seguida, diminuem com o aumento do teor em $\mathrm{Fe}$ total dos ortopiroxênios estudados.

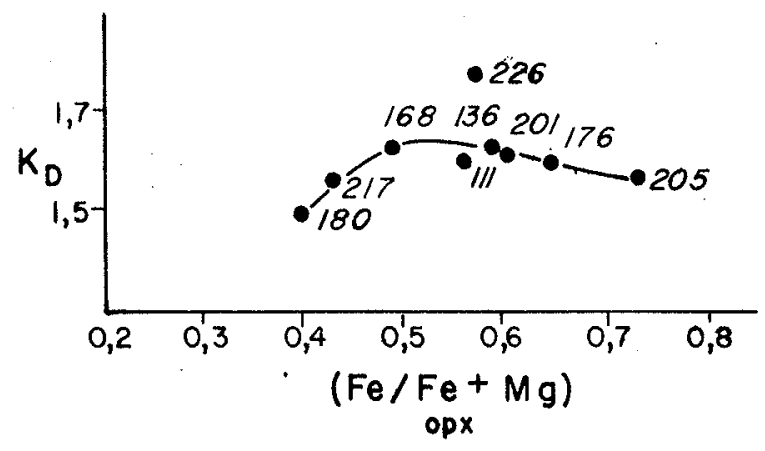

Figura 8 - Projeção do valor de $\mathrm{K}_{\mathrm{D}}$ contra a relação $\mathrm{Fe} / \mathrm{Fe}+\mathrm{Mg}$ dos ortopiroxênios

GEOTERMOMETRIA O geotermômetro ortopiroxênio-clinopiroxênio, ora utilizado, baseia-se na distribuição dos elementos $\mathrm{Fe}$ e $\mathrm{Mg}$ entre esses dois minerais. Esta distribuição, simples no caso de minerais como cordierita e granada, é complexa no caso dos piroxênios, pois ao invés de ser intercristalina ela passa a ser intracristalina, tendo-se em vista que o $\mathrm{Fe}$ e o $\mathrm{Mg}$ se distribuem em quatro posições dentro da estrutura, ou seja: $M_{1}$ opx, $M_{2} o p x, M_{1} c p x$ e $M_{2} c p x$, podendo-se fazer intervir a seguinte reação de troca:

$$
\mathrm{Fe}_{\mathrm{M}_{2}}^{+2}+\mathrm{Mg}_{\mathrm{M}_{1}} \underset{\mathrm{M}_{1}}{\longrightarrow} \mathrm{Fe}^{+2}+\mathrm{Mg}_{\mathrm{M}_{2}}
$$

tanto para orto como para clinopiroxenıs.

Além disso, conforme foi dito acima, o coeficiente de distribuição não é função simples da temperatura, mas depende também da composição.

Tendo em mente esses fatos, Wood e Banno (1973) calibraram um geotermômetro ortopiroxênio-clinopiroxênio, empregando o conceito de atividade. Com o auxílio de dados experimentais, eles derivaram uma equação que relaciona a temperatura à atividade do $\mathrm{Mg}$ nas posições $\mathrm{M}_{1}$ e $\mathrm{M}_{2}$. Embora a distribuição dos elementos proposta por esses autores seja aleatória, pois ainda não se conhece muito bem como ela se processa nas diversas posições, a utilização desse geotermômetro fornece valores próximos da temperatura exata, além de permitir a verificação da existência de gradientes geotérmicos. 
As temperaturas obtidas para os piroxênios de São José do Rio Pardo são fornecidas na Tab. II e variam de 795 a $883^{\circ} \mathrm{C}$, com um valor médio de $836 \pm 50^{\circ} \mathrm{C}$, considerando a precisão indicada por Wood e Banno (1973) e Hewins (1975). O fato das temperaturas terem sido calculadas, utilizando-se Fe total acarreta variações de $15^{\circ} \mathrm{C}$ em média para menos, conforme valores dados por Nantel (1977). Os maiores valores, referem-se aos tipos mais ricos em magnésio, decrescendo à medida que aumenta o teor em ferro dos piroxênios, acompanhando a tendência evidenciada no quadrilátero Di-Hd-En-Fs (Figs. 4 e 5). Voltando novamente à Fig. 2, observa-se que as mesmas amostras 180,217 e 168 , que ali se destacam, possuem também valores maiores de $T$, o que talvez possa ser uma explicação para os números mais elevados da razão $\mathrm{MgO} / \mathrm{FeO}$ exibidos por essas amostras.

$\hat{\mathrm{E}}$ ainda interessante mencionar que, geologicamente, existe uma boa distribuição das temperaturas obtidas. As amostras 201, 176 e 205 pertencentes, respectivamente, ao mesmo corpo, apresentam temperaturas de 801,802 e $795^{\circ} \mathrm{C}$; as amostras 111 e 136 , de ocorrência semelhante: 825 e $823^{\circ} \mathrm{C}$, o mesmo acontecendo com as amostras 217 e 180 , respectivamente, 848 e $872^{\circ} \mathrm{C}$. As amostras 168 e 226 ocorrem mais distantes das anteriores e seus valores não podem ser comparados. $O$ número de determinações é, no entanto, ainda insuficente para se evidenciar algum gradiente geotérmico para a região.

Comparando-se as temperaturas obtidas-a partir dos piroxênios com os valores calculados por Nantel (1977) para 60 pares ortopiroxênios-clinopiroxênios extraídos da literatura, conclui-se que as temperaturas de equilíbrio para a região de São Josê do Rio Pardo são idênticas àquelas encontradas em outros terrenos granulíticos do mundo.

Finalmente, é possível ainda se ter uma idéia do valor da pressão atuante, considerando o teor em $\mathrm{Al}_{2} \mathrm{O}_{3}$ dos piroxênios, conforme as avaliaçôes feitas por Wilson (1976) para as regiōes de Microwawe e Buningonia, Austrália (Fig. 6), ou seja 10 quilobárias para primeira e 8 quilobárias para a segunda. O exame da Fig. 6 permite verificar que o conteúdo em $\mathrm{Al}_{2} \mathrm{O}_{3}$ dos piroxênios brasileiros é menor que o obtido por aquele autor e, como conseqüência, os granulitos de São José do Rio Pardo devem ter-se equilibrado a pressões inferiores a 8 quilobárias. Essa conclusão vem confirmar as estimativas anteriores de Oliveira e Alves (1976), cerca de 6 quilobárias, tendo em vista a ocorrência na área de associações portadoras de wollastonita. Novamente se destacam as amostras 180 e 217 que, face ao conteúdo maior em $\mathrm{Al}_{2} \mathrm{O}_{3}$, caem na região de 8 quilobárias.

CONCLUSÕES Como conclusões ao presente trabalho, pode-se dizer que os pares de piroxênios estudados, cujo equilíbrio textural já fora verificado, apresentam. também um perfeito equilíbrio termodinâmico evidenciado a partir de suas composições químicas. Os "trends" de cristalização, bem como os coeficientes de distribuição $\mathrm{Fe}-\mathrm{Mg}$ (Figs. 4, 5 e 7) de orto e clinopiroxênios, fornecem indicações de que a cristalização ou recristalização se deu por metamorfismo. $O$ perfeito equilíbrio desses minerais, permite o emprego do geotermômetro de Wood e Banno (1973) para a avaliação da temperatura de formação (em torno de $836 \pm 50^{\circ} \mathrm{C}$ ). Além disso, os teores pouco elevados de $\mathrm{Al}_{2} \mathrm{O}_{3}$ dos orto e clinopiroxênios estudados (Fig. 6) permitem estimar que as pressões durante a fase principal de metamorfismo foram inferiores a 8 quilobărias. 
Quanto à relação da composição química dos piroxênios e das respectivas rochas, pode-se dizer que a razão $\mathrm{MgO} / \mathrm{FeO}$ dos minerais varia em parte com a razão $\mathrm{MgO} / \mathrm{FeO}$ das rochas, em especial como teor em $\mathrm{SiO}_{2}$. Contudo, parece que a temperatura e a pressão de equilíbrio atingidas durante a fase principal de metamorfismo representam fatores importantes a condicionar essa razão.

Agradecimentos Os autores desejam expressar seus agradecimentos ao Conselho Nacional de Desenvolvimento Científico e Tecnológico ( $\mathrm{CNPq}$ ) pelo auxílio financeiro, bem como ao Prof. Dr. Celso de Barros Gomes pela orientação durante os trabalhos de análise na microssonda.

\section{BIBLIOGRAFIA}

BENCE, A.E. \& ALBEE, A.L. - 1968 - Empirical correction factors for the electron microanalysis of silicates and oxides. J. Geol., 76: 382-403

BHATTACHARYYA, C. - 1971 - An evaluation of the chemical distinctions between igneous and metamorphic orthopyroxenes. Amer. Mineral., 56: 499-506

BROWN, G.M. - 1957 - Pyroxenes from the aearly and middle stages of fractionation of the Skaergaard intrusion, East Greenland. Min. Mag. 31: 511-543

BROWN, G.M. \& VINCENT, E.A. - 1963 - Pyroxenes from the late stage of fractionation of the Skaergaard intrusion, East Greenland. J. Petrol., 4: 175-196

CAPEDRI, S.; GOMES, G.B.; RIVALENTI, G. \& RUBERTI, E. - 1976 - Pyroxenes and olivines as indicators of the petrological evolution of the Ivrea-Verbano basic formation (Italian Western Alps). Tschermaks Min. Petr. Mitt., 23: 175-190

DAVIDSON, L.R. - 1968 - Variation in ferrous iron-magnesium distribution coefficients of metamorphic pyroxenes from Quairading, Western Australia. Contr. Miner. Petrol., 19: 239-259

DEER, W.A.; HOWIE, R.A. \& ZUSSMAN, J. - 1963 - Rock forming minerals, Vol II, Chain Silicates. Longmans, London

EWART, A.; BRYAN, W.B. \& GILL, J.B. - 1973 - Mineralogy and geochemistry of the younger volcanic island of Tonga, SW Pacific. J. Petrol., 14: 429-465

GIRARDI, V.A.V. - 1974 - Petrologia do complexo básico-ultrabásico de Piên, PR. Tese de Livre Docência. Instituto de Geociências, Universidade de São Paulo (inédito).

HEWINS, R.H. - 1975 - Pyroxene geothermometry of some granulite facies rocks. Contr. Miner. Petrol., 50:205-209

HOWIE, R.A. - 1955 - The geochemistry of the charnockites series of Madras, India. Trans. Royal Soc. Edinburgh, 62: 725-769

KRETZ, R. - 1963 - Distribution of magnesian and iron between orthopyroxenes and calcic pyroxenes in natural assemblages. J. Geol., 71:773-785

NANTEL, S. - 1977 - Le problème des équilibres cordierite-grenat et orthopyroxèneclinopyroxène en catazone. Application à la géothermo-barométrie dans le sud de la Province de Grenville. Tese, de Mestrado. Departamento de Geologia, Universidade de Montreal (inédito)

OLIVEIRA, M.A.F. de - 1972 - Geologia e petrologia da região de São José do Rio Pardo, São Paulo. Tese de Doutoramento. Instituto de Geociências, Universidade de São Paulo (inédito)

OLIVEIRA, M.A.F. de - 1973 - Petrologia das rochas metamórficas da região de São José do Rio Pardo, SP. Rev. Bras. Geoc., 3:257-278

OLIVEIRA, M.A.F. de \& ALVES, F.R. - 1974 - Geologia e petrografia da região de Caconde, SP. An. XXVIII Congr. Bras. Geol., 5: 133-143 
OLIVEIRA, M.A.F. de \& ALVES, F.R. - 1976 - Wollastonita em associações cálcicas de facies granulito, Caconde, SP: Rev. Bras. Geoc., 6:43-52

SOARES, R.M.C.; GOMES, C.B. \& RUBERTI, E. - no prelo - Coexisting pyroxenes in mafic and ultramafic rocks from Barra Velha, Santa Catarina, Brazil. Jornal de Mineralogia, Volume Especial Djalma Guimarães.

WILSON, A.F. - 1976 - Aluminium in coexisting pyroxenes as a sensitive indicator of changes in metamorphic grade within the mafic granulite terrane of the Fraser Range, Western Australia. Contr. Miner. Petrol., 56: 255-277

WOOD, B.J. \& BANNO, S. - 1973 - Garnet-orthopyroxene and orthopyroxene-clinopyroxene relationships in simple and complex systems. Contr. Miner. Petrol., 42: 109. 124 